\title{
A Comparative Study of the Morphology and Viability of Hyphae of Penicillium expansum and Phytophthora nicotianae during Freezing and Thawing
}

\author{
By D. SMITH, ${ }^{*}$ G. E. COULSON ${ }^{2}$ AND G. J. MORRIS ${ }^{2}$ \\ ${ }^{1}$ Commonwealth Mycological Institute, Ferry Lane, Kew, Surrey TW9 3AF, UK \\ ${ }^{2}$ Institute of Terrestrial Ecology, Culture Centre of Algae and Protozoa, 36 Storey's Way, \\ Cambridge CB3 ODT, UK
}

(Received 8 January 1986; revised 18 February 1986)

\begin{abstract}
The changes in morphology of Penicillium expansum Link and Phytophthora nicotianae Van Breda de Haan during freezing and thawing in a growth medium with and without the cryoprotective additive glycerol were examined with a light microscope fitted with a temperature-controlled stage. Viability of $0.5-1.0 \mathrm{~mm}$ diameter colonies of both fungi was determined after equivalent rates of cooling to $-196^{\circ} \mathrm{C}$ in the presence or absence of glycerol. In $P$. expansum shrinkage occurred in all hyphae at rates of cooling of less than $15^{\circ} \mathrm{C} \mathrm{min}{ }^{-1}$; at faster rates intracellular ice nucleation occurred. The addition of glycerol increased the rate of cooling at which $50 \%$ of the hyphae formed intracellular ice from $18{ }^{\circ} \mathrm{C} \mathrm{min}{ }^{-1}$ to $55^{\circ} \mathrm{C} \mathrm{min}-1$. This species was particularly resistant to freezing injury and recovery was $>60 \%$ at all rates of cooling examined. At rapid rates of cooling recovery occurred in hyphae in which intracellular ice had nucleated. In contrast, during the cooling of $P h$. nicotianae in the growth medium, shrinkage occurred and no samples survived on thawing from $-196^{\circ} \mathrm{C}$. However, on the addition of glycerol, shrinkage during freezing decreased and viable hyphae were recovered upon thawing; at rates of cooling over $10^{\circ} \mathrm{C} \mathrm{min}^{-1}$ the loss of viability was related to glycerolinduced osmotic shrinkage during cooling rather than to the nucleation of intracellular ice.
\end{abstract}

\section{INTRODUCTION}

Studies of the biochemistry and biophysics of cellular injury are essential for an understanding of ecophysiology at low temperatures and for the improvement of methods for long-term preservation. The stresses that cells are exposed to during freezing and thawing are well-defined (Taylor, 1986). When freezing is initiated in a dilute aqueous solution only a proportion of the water undergoes transition to ice and the gases and solutes in the residual aqueous solution become more concentrated. Cells in suspension are exposed to hypertonic solutions during freezing and the cellular morphology and viability are determined by the rate of cooling. At 'slow' rates of cooling extensive shrinkage occurs, whilst at faster rates of cooling there is insufficient time for osmotic equilibrium to be maintained and intracellular ice may nucleate. 'Rapid' and 'slow' rates of cooling have no absolute values and vary with cell-type and the presence or absence of cryoprotective additives.

Coulson et al. (1986) used a light microscope fitted with a temperature-controlled stage to observe the hyphae of Penicillium expansum during freezing and thawing. At slow rates of cooling $\left(<15^{\circ} \mathrm{C} \mathrm{min}{ }^{-1}\right)$ extensive shrinkage of the hyphae, without distinct plasmolysis, was observed. Cooling at rates greater than $50^{\circ} \mathrm{C} \mathrm{min}{ }^{-1}$ induced intracellular ice formation in all hyphae. At intermediate rates, shrinkage and intracellular ice nucleation were observed, occasionally within the same hypha. At rates of cooling at which intracellular ice formed, nucleation occurred at $-14^{\circ} \mathrm{C}$ and was independent of the rate of cooling within the range 20 to $100^{\circ} \mathrm{C} \mathrm{min}-1$. Here we extend these studies to examine the morphology of Phytophthora 
nicotianae, a pathogen of citrus causing fruit rot. This fungus is a representative of the Mastigomycotina, a group that presents particular problems in cryopreservation (Smith, 1982). The effects of the presence and absence of the cryoprotective additive glycerol on the hyphae during freezing are examined for both $P$ h. nicotianae and $P$. expansum and compared with colony viability after different rates of cooling to $-196{ }^{\circ} \mathrm{C}$. It is generally assumed that one of the major stresses associated with freezing is the formation of hypertonic solutions and therefore the effects of hypertonic solutions on morphology and viability were also examined.

\section{METHODS}

Preparation of fungal cultures. Conidia of P. expansum (IMI 174158) were inoculated into Czapek-Dox broth and hemp seed medium. Agar blocks cut from the edge of colonies of Ph. nicotianae (IMI 158733) on oat agar (Smith \& Onions, 1983) were inoculated into onion or hemp seed medium (Smith \& Onions, 1983). The cultures were incubated for 48 to $72 \mathrm{~h}$ and agitated occasionally to break up the colonies, which were non-sporulating and in the form of thin mycelial mats. Intact colonies $0.5-1.0 \mathrm{~mm}$ in diameter were selected for observation and transferred from broth culture to the stage of the cryomicroscope with an Eppendorf multipipette. The colonies of $P$. expansum grown in hemp seed medium were prepared for comparison of the behaviour of the hyphae when grown on different media. The colonies produced were observed on the cryomicroscope at a limited range of cooling rates only and were not used in the viability tests. There were at least three replicates prepared for each cooling rate.

Cooling at different rates to $-196^{\circ} \mathrm{C}$. Colonies were placed in $0.5 \mathrm{ml}$ of either growth medium or glycerol $(10 \%$, $\mathrm{v} / \mathrm{v}$ ) in a $12 \times 35 \mathrm{~mm}$ sterile polypropylene tube (Nunc). Colonies in growth medium were frozen without further incubation, those in glycerol were equilibrated at approximately $20^{\circ} \mathrm{C}$ for $1 \mathrm{~h}$. The tubes were cooled at different rates to $-60^{\circ} \mathrm{C}$ by the technique previously described (Morris \& Farrant, 1972) before being cooled rapidly to $-196^{\circ} \mathrm{C}$ in liquid nitrogen. The rate of cooling, determined from the time required to cool between -5 and $-60^{\circ} \mathrm{C}$, was measured from a replicate sample using a copper-constantan thermocouple (28 SWG) connected to a Kipp-Zonen potentiometric recorder (model BD5). The hyphae were thawed after $5 \mathrm{~min}$ at $-196^{\circ} \mathrm{C}$ by rapid agitation of the tube in a water bath at $+30^{\circ} \mathrm{C}$ until the last crystals of ice had melted. There were at least three replicates for each cooling rate and counts were done in duplicate.

Assay of viability. Regrowth was determined by transferring colonies of $P$. expansum onto Czapek-Dox agar and colonies of $P h$. nicotianae on to oat agar (Smith \& Onions, 1983). The colonies of $P$. expansum were scored between 36 and $48 \mathrm{~h}$ on the agar medium and checked again after $72 \mathrm{~h}$. The colonies of $P h$. nicotianae were scored after 4 to $7 \mathrm{~d}$ on the recovery medium.

Cryomicroscopy. During freezing and thawing hyphae were observed on a cryomicroscope conduction stage (McGrath, 1986), a microcomputer (Apple IIe) being used for temperature control of the stage heater. They were cooled from 20 to $5{ }^{\circ} \mathrm{C}$ at a rate of $10^{\circ} \mathrm{C} \mathrm{min}^{-1}$, held at $5{ }^{\circ} \mathrm{C}$ for $0.5 \mathrm{~min}$, and then cooled at different linear rates. Colonies in the growth medium were cooled to -30 or $-50^{\circ} \mathrm{C}$, and those in glycerol to $-50^{\circ} \mathrm{C}$. Samples were maintained isothermally at the minimum temperature for $30 \mathrm{~s}$ and rewarmed at $50{ }^{\circ} \mathrm{C} \mathrm{min}{ }^{-1}$ to $20^{\circ} \mathrm{C}$. Three replicates or more were observed at each cooling rate.

Diffusion stage. The dynamic response of individual hyphae to alterations in the osmolality of the surrounding medium was examined on a microscope diffusion stage as described by McGrath (1985).

Light microscopy. Observations were made with a Leitz Dialux 22 microscope fitted with a $40 / 0 \cdot 7$ objective combined with a $2 \times$ magnification changer. Data were recorded on video (Hitachi HV-65 camera, Sony U-matic recorder model VO-5630) using a video time generator (Panasonic model WJ-810) to record times. The recorded data were played back for analysis on a video monitor (Hitachi model VM-906a) and photographs were taken directly from the video screen using a Polaroid land camera (model CU-5, film type 667).

Effects of hypertonic solutions. Colonies of both fungi were grown and harvested as described above and immersed in a range of $\mathrm{NaCl}$ solutions $(1 \cdot 5,2,2 \cdot 5,3$ and $3.5 \mathrm{M})$ for $5 \mathrm{~min}$ at approximately $20^{\circ} \mathrm{C}$. Colonies were then transferred to growth medium for $5 \mathrm{~min}$ before inoculation onto agar medium. Three replicates were prepared for each $\mathrm{NaCl}$ solution.

\section{RESULTS}

Viability after freezing and thawing. Regrowth was evident in $>60 \%$ of the colonies of $P$. expansum frozen to $-196^{\circ} \mathrm{C}$ in the growth medium at all rates of cooling examined (Fig. 1). Growth from the viable colonies after freezing and thawing was similar to that observed from unfrozen controls. The addition of glycerol $(10 \%, \mathrm{v} / \mathrm{v})$ increased the extent of recovery and, at cooling rates of less than $20^{\circ} \mathrm{C} \mathrm{min}^{-1}$, gave viabilities of over $90 \%$. After freezing in both growth medium and glycerol viability was reduced at faster rates of cooling. When colonies were 


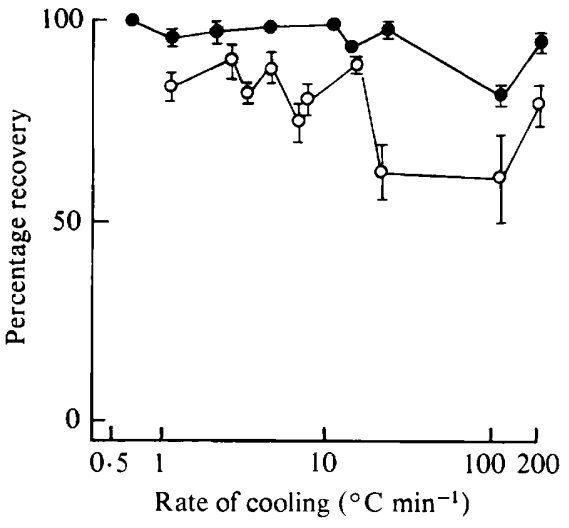

Fig. 1

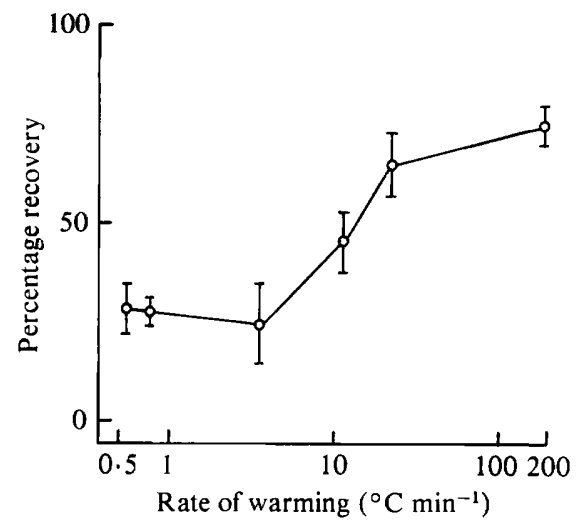

Fig. 2

Fig. 1. Recovery of colonies of $P$. expansum after different rates of cooling to $-196{ }^{\circ} \mathrm{C}$. At least 50 colonies were frozen at each cooling rate in either growth medium $(O)$ or glycerol $(10 \%, \mathrm{v} / \mathrm{v})(\mathrm{O})$. Counts were in duplicate and SDs calculated to show the variation between plate counts. The bars represent one SD.

Fig. 2. Recovery of colonies of $P$. expansum after different rates of warming from $-196^{\circ} \mathrm{C}$. Colonies were cooled to $-196^{\circ} \mathrm{C}$ at $200^{\circ} \mathrm{C} \mathrm{min}^{-1}$ in growth medium. The bars represent one SD.

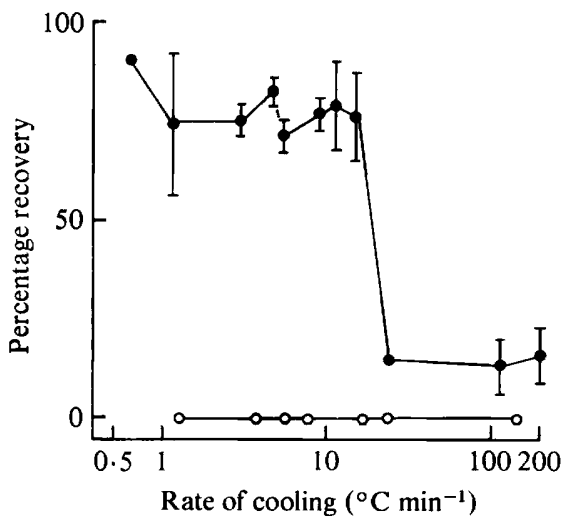

Fig. 3. Recovery of $P h$. nicotianae after different rates of cooling to $-196^{\circ} \mathrm{C}$. Colonies were frozen in either growth medium $(O)$ or glycerol $(10 \%, v / v)(O)$. The bars represent one SD.

cooled rapidly in growth medium, recovery was highest after rapid rates of warming; however, even at rates of warming of less than $1{ }^{\circ} \mathrm{C} \mathrm{min}-1$ regrowth, albeit slow, was evident in approximately $30 \%$ of colonies (Fig. 2).

There was no regrowth of colonies of $P h$. nicotianae after freezing to and thawing from $-196{ }^{\circ} \mathrm{C}$ in growth medium. In the presence of glycerol, viable colonies recovered, survival being dependent on the rate of cooling (Fig. 3). Viability was $>70 \%(n=15)$ at rates of cooling of less than $11{ }^{\circ} \mathrm{C} \mathrm{min}^{-1}$; at faster rates of cooling the recovery fell to $<20 \%(n=9)$.

Change in morphology during freezing. The morphology of hyphae of $P$. expansum during freezing and thawing depended on the rate of cooling and the presence of glycerol. As previously demonstrated for hyphae frozen in Czapek-Dox media (Coulson et al., 1986), slow rates of cooling $\left(<15^{\circ} \mathrm{C} \mathrm{min}{ }^{-1}\right)$ induced extensive shrinkage, whilst at faster rates $\left(>50{ }^{\circ} \mathrm{C} \mathrm{min}^{-1}\right)$ intracellular ice formed during freezing and gas bubbles were observed within hyphae during rapid rewarming. At lower rates of rewarming extracellular ice recrystallized and localized melting was evident within hyphae at $-12{ }^{\circ} \mathrm{C}$; the formation of intracellular gas bubbles was not observed (Fig. 4). The colonies grown in hemp seed medium behaved similarly: at a cooling 

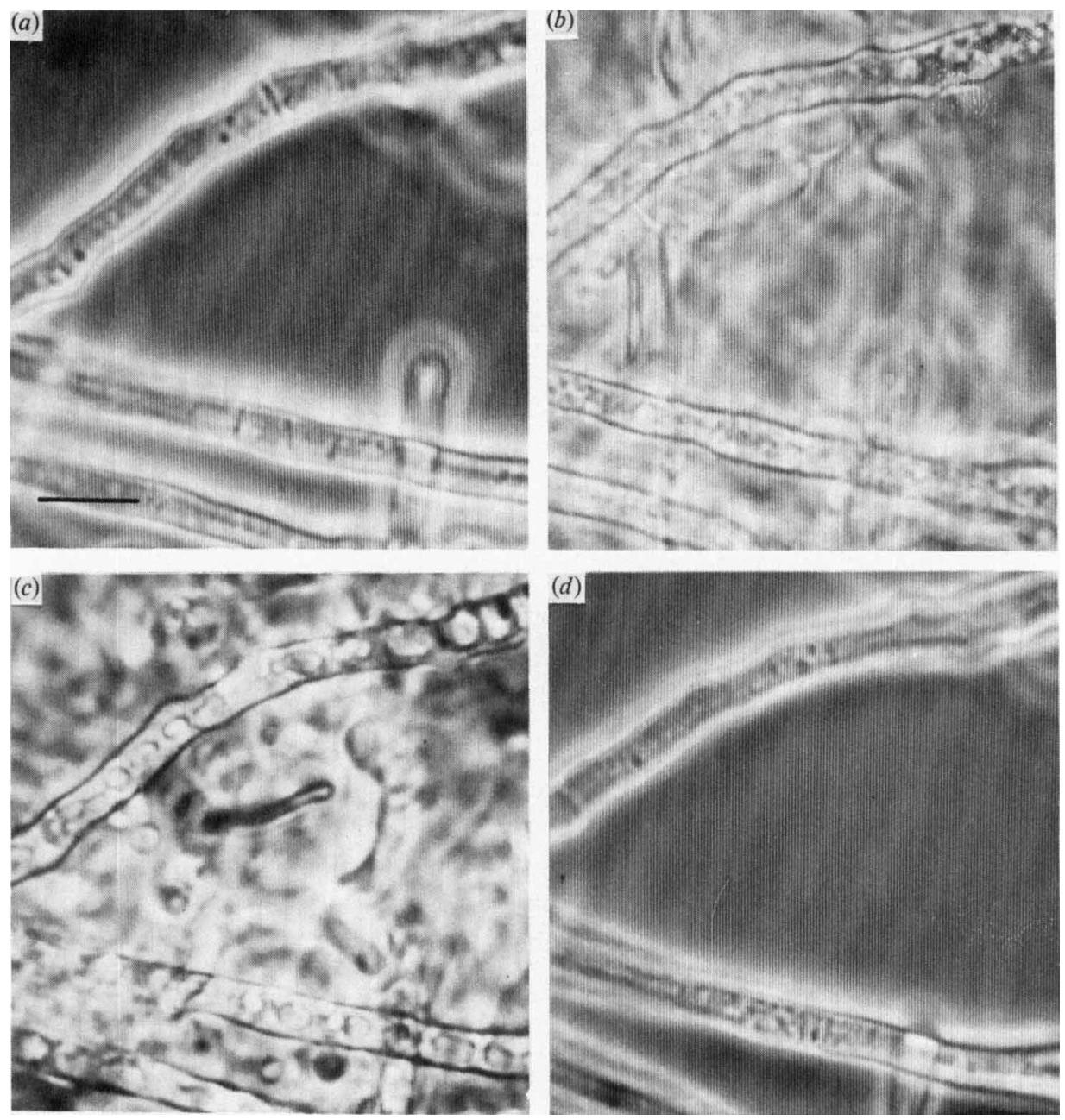

Fig. 4. Light microscopy of $P$. expansum. (a) Unfrozen; (b) after cooling at a rate of $50{ }^{\circ} \mathrm{C} \mathrm{min}^{-1}$ in growth medium to $-50^{\circ} \mathrm{C}$; $(c)$ during rewarming at a rate of $5^{\circ} \mathrm{C} \min ^{-1}$ at $-10^{\circ} \mathrm{C}$, where localized melting can be seen; $(d)$ thawed. Bar, $10 \mu \mathrm{m}$.

rate of $10{ }^{\circ} \mathrm{C} \mathrm{min}^{-1}$ all hyphae shrank; at $20^{\circ} \mathrm{C} \mathrm{min}-1$ approximately $50 \%$ shrank while the remainder showed intracellular ice nucleation; and at $50{ }^{\circ} \mathrm{C} \mathrm{min}-1$ all hyphae showed intracellular ice.

The addition of glycerol $(10 \%, \mathrm{v} / \mathrm{v})$ modified the morphology of $P$. expansum during freezing and thawing. During cooling at $10^{\circ} \mathrm{C} \mathrm{min}-1$ no alteration was evident; hyphae remained unshrunken during freezing. At rates of $50^{\circ} \mathrm{C} \mathrm{min}^{-1}$ or more hyphae became granular throughout the whole of their observed length. This was assumed to be due to the formation of intracellular ice. Upon rewarming gas bubbles formed within hyphae. These bubbles increased in size and returned to solution upon melting of extracellular ice.

The response of $P h$. nicotianae differed greatly from that of $P$. expansum. No intracellular ice was formed in hyphae in growth medium (see Fig. 7) and the protoplast and hyphal wall shrank extensively at all rates of cooling examined, illustrated during rapid cooling in Fig. 5. In many hyphae plasmolysis was evident and the hyphal wall often appeared to be ridged or folded; on thawing the cytoplasmic organization was disrupted. Intracellular ice was not observed during freezing in glycerol and shrinkage of the hyphae was determined by the rate of cooling. 

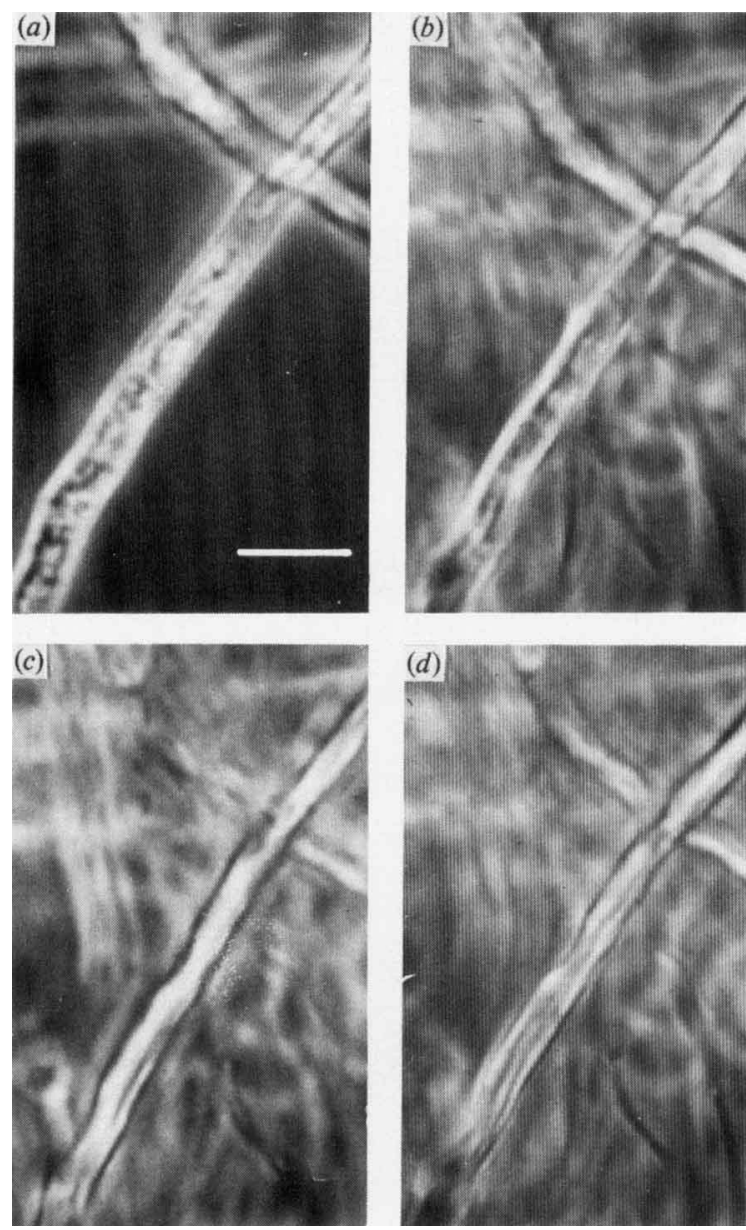

Fig. 5. Light microscopy of $P h$. nicotianae during cooling at a rate of $100^{\circ} \mathrm{C} \mathrm{min}^{-1}$ in growth medium. (a) Unfrozen; $(b)-10^{\circ} \mathrm{C} ;(c)$ $-30^{\circ} \mathrm{C} ;(d)-50^{\circ} \mathrm{C}$. Bar, $10 \mu \mathrm{m}$.

Quantitative analysis. During the freezing of $P$. expansum in growth medium, maximum shrinkage was observed at slow rates of cooling. As the rate of cooling increased less shrinkage occurred, and at $100^{\circ} \mathrm{C} \mathrm{min}-1$ hyphae reached low temperatures without significant reduction in diameter (Fig. 6). No significant shrinkage occurred during freezing in glycerol at any rate of cooling examined. Glycerol also modified the rate and temperature at which intracellular nucleation occurred (Fig. 7); at rates of cooling of less than $35^{\circ} \mathrm{C} \mathrm{min}-1$ intracellular ice was not evident during cooling. The incidence of intracellular ice formation increased sharply between the rates of 35 and $40^{\circ} \mathrm{C} \mathrm{min}^{-1}$. To allow comparison of different treatments, the rate of cooling at which $50 \%$ of hyphae formed intracellular ice was determined graphically. For P. expansum in growth medium this was at $18^{\circ} \mathrm{C} \mathrm{min}-1$ compared with $55^{\circ} \mathrm{C} \mathrm{min}-1$ in the presence of glycerol.

By contrast, during freezing of $P h$. nicotianae in growth medium the diameter of the hyphae was reduced to $60 \%$ of that of unfrozen controls at all cooling rates examined (Fig. 8). The hyphal diameter after cooling in the presence of glycerol was dependent on the rate of cooling. At rates of less than $5{ }^{\circ} \mathrm{C} \mathrm{min}{ }^{-1}$ shrinkage did not occur; at intermediate rates of cooling (10 to $70{ }^{\circ} \mathrm{C} \mathrm{min}^{-1}$ ) there was a $20 \%$ reduction in diameter; at faster rates less shrinkage occurred.

Hypertonic stress. Colonies of $P$. expansum were more resistant to the stress of exposure to and removal from hypertonic solutions of $\mathrm{NaCl}$ than was $P$ h. nicotianae (Fig. 9). Between 25 and 100 colonies were immersed in each concentration of $\mathrm{NaCl}$. The proportion of survivors and the deviation from the mean were calculated for each replicate. 


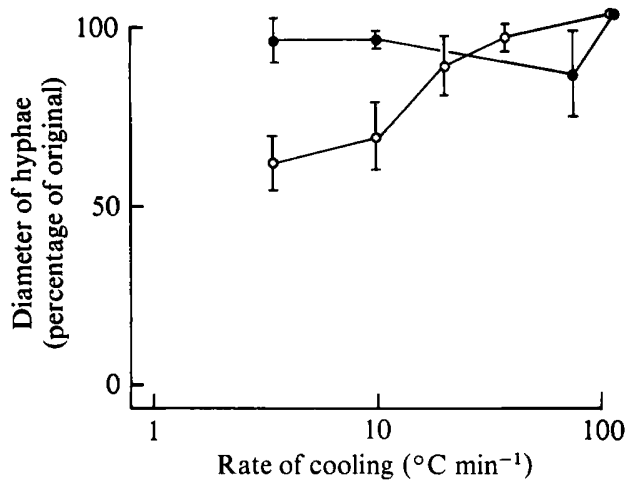

Fig. 6

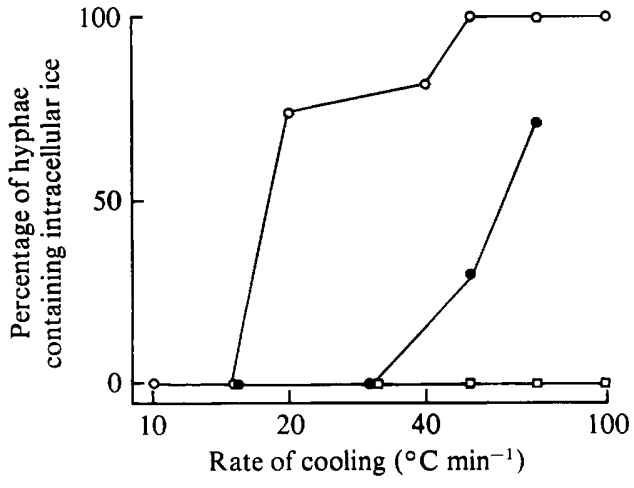

Fig. 7

Fig. 6. Diameter of hyphae (percentage of unfrozen) of $P$. expansum after different rates of cooling to $-30{ }^{\circ} \mathrm{C}$. Hyphae were in either growth medium $(\mathrm{O})$ or glycerol $(10 \%, \mathrm{v} / \mathrm{v})(\mathrm{O})$. The bars represent one SD.

Fig. 7. Incidence of intracellular ice formation within hyphae of $P$. expansum, where the hyphae were in either growth medium $(O)$ or glycerol $(10 \%, v / v)(O)$, and $P h$. nicotianae, where the hyphae were in growth medium $(\square)$, at different rates of cooling.

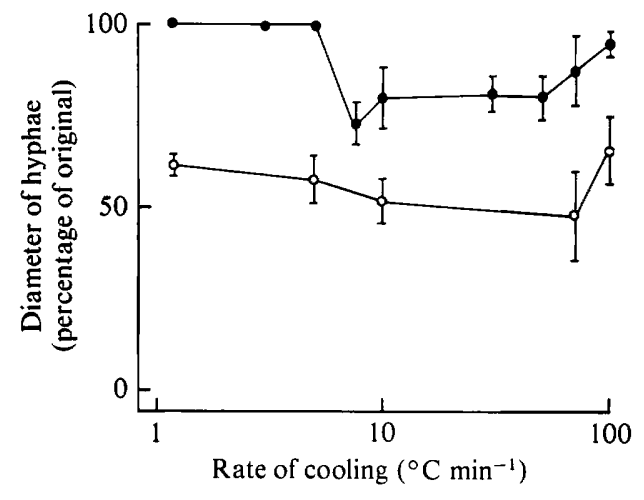

Fig. 8

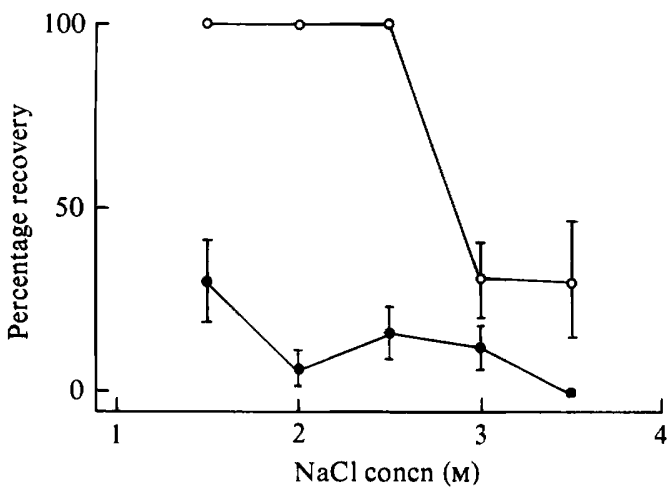

Fig. 9

Fig. 8. Diameter of hyphae (percentage of unfrozen) of $P h$. nicotianae after different rates of cooling to $-30^{\circ} \mathrm{C}$. Hyphae were in either growth medium $(\mathrm{O})$ or glycerol $(10 \%, \mathrm{v} / \mathrm{v})(\mathrm{O})$. The bars represent one SD.

Fig. 9. Recovery of colonies of $P$ h. nicotianae $(O)$ and $P$. expansum $(O)$ after hypertonic stress. Colonies were exposed to solutions of $\mathrm{NaCl}$ for $5 \mathrm{~min}$ at $20^{\circ} \mathrm{C}$ and then returned to an isotonic medium. The bars represent one SD.

The morphology of hyphae on exposure to a hypertonic solution of $\mathrm{NaCl}$ on a diffusion stage differed between the species (Fig. 10). Exposure of $P$. expansum to $3 \mathrm{M}-\mathrm{NaCl}$ induced localized plasmolysis within $30 \mathrm{~s}$; on its return to isotonic solutions the protoplast and hyphal wall reexpanded, and hyphae responded similarly to a second hypertonic challenge. By contrast, in $P h$. nicotianae exposed to $2 \mathrm{M}-\mathrm{NaCl}$ a greater degree of plasmolysis was observed and was complete within 10 s. Many hyphae re-expanded in the hypertonic solution before their return to isotonic solution. All hyphae failed to respond to further hypertonic stress. 

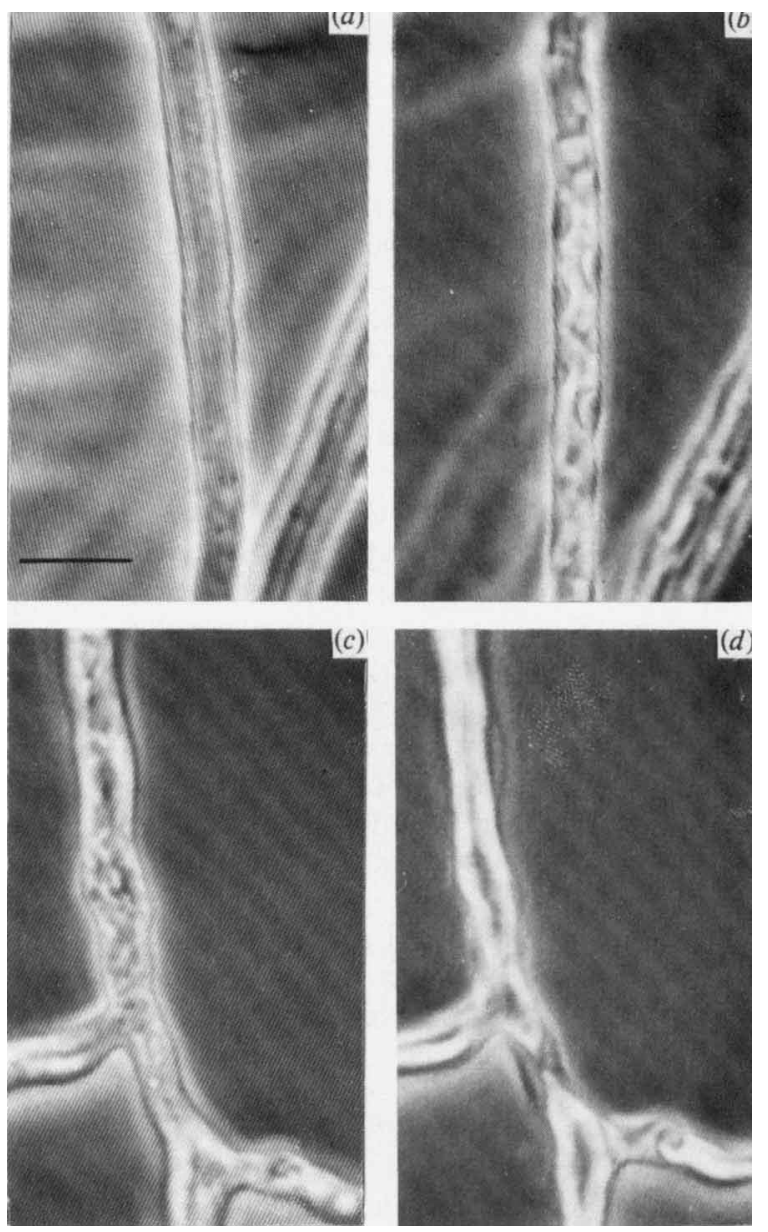

Fig. 10. Light microscopy of the same field of hyphae before and after exposure to hypertonic $\mathrm{NaCl}$. (a) P. expansum control; (b) after exposure to $\mathrm{NaCl}(3 \mathrm{M})$ for $1 \mathrm{~min}$; (c) $\mathrm{Ph}$. nicotianae control; (d) after exposure to $\mathrm{NaCl}$ (2 $\mathrm{M})$ for $1 \mathrm{~min}$. Bar, $10 \mu \mathrm{m}$.

\section{DISCUSSION}

Many cells from different groups of organisms have an optimum rate of cooling, survival decreasing at both faster and slower rates (see Mazur, 1970). Cellular injury at sub-optimal rates of cooling has generally been ascribed to the damaging effects of prolonged exposure to hypertonic solutions. At supra-optimal rates of cooling death has been correlated with the nucleation of intracellular ice. However, this relationship between the morphology during freezing and survival on thawing does not apply to the two species of fungi examined in this study.

P. expansum was highly resistant to both shrinkage at slow cooling rates and intracellular ice formation at fast cooling rates. The formation of intracellular ice is considered to be a lethal stress to most cells (Mazur, 1977), but $P$. expansum was resistant to such injury. The only other eukaryotic cell-type in which vegetative cells are known to be resistant to both hypertonic stress and the nucleation of intracellular ice is the unicellular green alga Chlorella protothecoides (Morris, 1976).

Ph. nicotianae was not so resistant and was killed by all rates of cooling without the cryoprotectant additive glycerol. Intracellular ice was not observed but extensive shrinkage occurred. These observations suggest that during freezing the water transport processes of these hyphae are considerably faster than those of $P$. expansum. Amongst other cells examined by cryomicroscopy only human erythrocytes have a faster critical cooling rate, with $50 \%$ nucleation 
at $540{ }^{\circ} \mathrm{C} \min ^{-1}$ (Diller et al., 1976). This high permeability to water means that hyphae shrink (or collapse) rapidly on exposure to osmotic stress. The response is damaging and, compared with $P$. expansum, colonies or $P h$. nicotianae are extremely sensitive to osmotic stress at $20^{\circ} \mathrm{C}$. In the shrunken state a loss of plasmalemma function occurred, as many hyphae re-expanded while suspended in hypertonic solution, and these hyphae did not respond to further hypertonic challenge.

During the freezing of P. expansum in glycerol, shrinkage of hyphae was reduced, presumably because there was sufficient time for the equilibrium between extracellular glycerol and the hyphae to be attained. The presence of glycerol increased the critical rates of cooling. Such a modification of intracellular nucleation after the addition of cryoprotective additives has been observed with many cells from different groups of organisms (Leibo, 1977; Morris et al., 1986) and may be due to alteration of the characteristics of water transport, direct effects on membranes or increasing the amount of residual unfrozen fraction at any temperature.

After freezing Ph. nicotianae in $10 \%$ glycerol at slow rates of cooling $\left(<10^{\circ} \mathrm{C} \mathrm{min}-1\right)$, hyphae remained unshrunken and viable, presumably as a result of the avoidance of osmotic stress and the low toxicity of concentrated solutions of glycerol at reduced temperatures. At faster rates of cooling $\left(>10^{\circ} \mathrm{C} \mathrm{min}^{-1}\right)$ shrinkage occurred as there was insufficient time for osmotic equilibrium, which was incompatible with high recovery. The reduction in survival at cooling rates faster than $10{ }^{\circ} \mathrm{C} \mathrm{min}^{-1}$ in the presence of glycerol was not due to the formation of intracellular ice and is therefore concluded to be due to the osmotic stress imposed by glycerol during freezing. The loss of viability of the unicellular green alga $C y$ lindrocystis brebissonii at intermediate rates of cooling in the presence of the cryoprotective additive dimethylsulphoxide has also been correlated to cryoprotective additive-induced shrinkage during freezing rather than to nucleation of intracellular ice (Morris et al., 1986).

The two species studied represent different groups of fungi that are widely separated. $P$. expansum is a Hyphomycete whereas $P h$. nicotianae belongs to the Mastigomycotina (see Hawksworth et al., 1983). The latter is regarded by some as a protist and not a true fungus (Kendrick, 1985). Their differences are again emphasized by their responses to cooling.

These data suggest that the hypothesis of freezing injury generally accepted for a wide range of cells from different organisms (Mazur, 1970) does not apply to fungi. Further studies are required to establish the relationship for fungi between the morphology during freezing and hyphal viability upon thawing. Such data are a prerequisite for the development of specific methods for the cryopreservation of fungi.

\section{REFERENCES}

Coulson, G. E., Morris, G. J. \& Smith, D. (1986). A crymicroscopic study of Penicillium expansum hyphae during freezing and thawing. Journal of General Microbiology 132, 183-190.

Diller, K. R., Cravalho, E. G. \& Huggins, C. E. (1976). An experimental study of freezing in erythrocytes. Journal of Medical and Biological Engineering 14, 321-326.

Hawksworth, D. L., Sutton, B. C. \& Ainsworth, G. C. (1983). Ainsworth \& Bisby's Dictionary of the Fungi, 7th edn. Kew: Commonwealth Mycological Institute.

KENDRICK, B. (1985). The Fifth Kingdom. Waterloo, Ontario: Mycologue Publications.

LEIBO, S. P. (1977). Fundamental cryobiology of mouse ova and embryos. In The Freezing of Mammalian Embryos, Ciba Foundation Symposium 52 (New Series), pp. 69-96. Edited by K. Elliot \& J. Whelan. Amsterdam: Elsevier.

MCGrath, J. J. (1985). A microscope diffusion chamber for the determination of the equilibrium and non-equilibrium osmotic response of individual cells. Journal of Microscopy 139, 249-265.
MCGrath, J. J. (1986). Temperature controlled cryogenic light microscopy - an introduction to cryomicroscopy. In The Effects of Low Temperatures on Biological Systems. Edited by B. W. W. Grout \& G. J. Morris. London: Edward Arnold (in the Press). MAzUR, P. (1970). Cryobiology: the freezing of biological systems. Science 168, 939-949.

MAZUR, P. (1977). The role of intracellular freezing in the death of cells cooled at supraoptimal rates. Cryobiology 14, 251-272.

MoRRIS, G. J. (1976). The cryopreservation of Chlorella. 1. Interactions of rate of cooling, protective additive and warming rate. Archives of Microbiology 107, 57-62.

MorRIS, G. J. \& FARrant, J. (1972). Interactions of cooling rate and protective additive on the survival of washed human erythrocytes. Cryobiology 9, 173181.

Morris, G. J., Coulson, G. E. \& Engels, M. (1986). A cryomicroscopic study of Cylindrocystis brebissonii De Bary and two species of Micrasterias (Conjugatophyceae, Chlorophyta) during freezing and thawing. Journal of Experimental Botany (in the Press). 
SMITH, D. (1982). Liquid nitrogen storage of fungi. TAYLOR, M. J. (1986). Physico-chemical principles of Transactions of the British Mycological Society 79, low temperature biology. In The Effects of Low 415-421.

SMITH, D. \& ONIONS, A. H. S. (1983). The Preservation and Maintenance of Living Fungi. Kew: Commonwealth Mycological Institute.

Temperatures on Biological Systems. Edited by B. W. W. Grout \& G. J. Morris. London: Edward Arnold (in the Press). 